\title{
Microstructure and Mechanical Properties of Ti-Nb Alloys Prepared by Mechanical Alloying and Spark Plasma Sintering
}

\author{
Damian Kalita, Łukasz Rogal, Tomasz Czeppe, Anna Wójcik, Aleksandra Kolano-Burian, Przemysław Zackiewicz, Bogusz Kania, \\ and Jan Dutkiewicz
}

(Submitted August 19, 2019; in revised form September 24, 2019; published online November 7, 2019)

\begin{abstract}
The effect of $\mathrm{Nb}$ content on microstructure, mechanical properties and superelasticity was studied in $\mathrm{Ti}-\mathrm{Nb}$ alloys fabricated by powder metallurgy route using mechanical alloying and spark plasma sintering. In the microstructure of the as-sintered materials, undissolved $\mathrm{Nb}$ particles as well as precipitations of $\alpha$-phase at grain boundaries of $\beta$-grains were observed. In order to improve the homogeneity of the materials, additional heat treatment at $1250{ }^{\circ} \mathrm{C}$ for $24 \mathrm{~h}$ was performed. As a result, $\mathrm{Nb}$ particles were dissolved in the matrix and the amount of $\alpha$-phase was reduced to 0.5 vol.\%. Yield strength of the as-sintered alloys decreased with $\mathrm{Nb}$ content from $949 \mathrm{MPa}$ for $\mathrm{Ti}-14 \mathrm{Nb}$ to $656 \mathrm{MPa}$ for $\mathrm{Ti}-26 \mathrm{Nb}$, as a result of the decreasing amount of $\alpha$-phase precipitations. Heat treatment did not have a significant effect on mechanical properties of the alloys. A maximum recoverable strain of $3 \%$ was obtained for heat-treated $\mathrm{Ti}-14 \mathrm{Nb}$, for which $A_{\mathrm{s}}$ and $A_{\mathrm{f}}$ temperatures were -12.4 and $2.2^{\circ} \mathrm{C}$, respectively.
\end{abstract}

Keywords martensitic transformation, mechanical alloying, sintered alloy, superelasticity, titanium alloys

\section{Introduction}

Ti-Nb-based alloys are considered as materials for orthopedic implants due to their excellent biocompatibility (Ref 1), low elastic modulus (Ref 2) and good superelastic properties (Ref 3). The superelastic behavior of Ti-Nb alloys is connected with the thermo-elastic martensitic transformation between bodycentered cubic (BCC) $\beta$ parent phase and orthorhombic $\alpha$, martensite phase (Ref 3 ). In the case of pure titanium lowtemperature HCP (hexagonal close packed), $\alpha$-phase transforms to $\beta$-phase at $882^{\circ} \mathrm{C}$. However, by adding elements such as $\mathrm{Nb}, \mathrm{Ta}, \mathrm{Mo}$, the high-temperature $\beta$-phase can be stabilized in room temperature (RT) (Ref 4). In binary $\mathrm{Ti}-\mathrm{Nb}$ system, an addition of 1 at. $\%$ of $\mathrm{Nb}$ to $\beta$-Ti decreases $M_{\mathrm{s}}$ temperature by $40{ }^{\circ} \mathrm{C}$ and an addition of $26-27$ at. $\%$ allows to obtain $M_{\mathrm{s}}$ temperature slightly below room temperature (RT), which ensures optimal RT superelastic properties (Ref 5,6). Theoret-

This article is an invited submission to JMEP selected from presentations at The XXII Physical Metallurgy and Materials Science Conference: Advanced Materials and Technologies (AMT 2019) held on June 9-12, 2019, in Bukowina Tatrzańska, Poland, and has been expanded from the original presentation.

Damian Kalita, Lukasz Rogal, Tomasz Czeppe, Anna Wójcik, Bogusz Kania, and Jan Dutkiewicz, Institute of Metallurgy and Materials Science, Polish Academy of Sciences, Reymonta 25 St., 30059 Kraków, Poland; and Aleksandra Kolano-Burian and Przemysław Zackiewicz, Institute of Non-Ferrous Metals, Sowinskiego 5 St., 44-100 Gliwice, Poland. Contact e-mail: d.kalita@imim.pl.

ical calculation shows that alloys which contain 26 at.\% of $\mathrm{Nb}$ maximum strain transformation along [011] direction can reach about $3 \%$ (Ref 3 ). This value can be increased by reducing the concentration of $\mathrm{Nb}$ or by replacing $\mathrm{Nb}$ by other elements such as Ta, Mo, $\mathrm{Zr}$ (Ref 3, 6). The extensive research is focused on shape-memory characteristic of Ti-Nb-based alloys obtained through casting and cold-working processes. For example, Kim et al. (Ref 3 ) reported a maximum recovery strain of $4.2 \%$ in cold-rolled Ti-26Nb alloy aged at $400{ }^{\circ} \mathrm{C}$. Aging of superelastic Ti-Nb alloys is required in order to obtain stable superelastic behavior as a result of the formation of nanometric precipitations of athermal $\omega$-phase which increase critical stress for slip deformation in those alloys (Ref 7, 8). Another way for increasing critical stress for slip deformation is the addition of interstitial elements such as $\mathrm{O}$ or $\mathrm{N}$. It was confirmed that an addition of 2 at. $\%$ of oxygen to $\mathrm{Ti}-22 \mathrm{Nb}$ increases critical stress for slip deformation up to $890 \mathrm{MPa}$, but also reduces the maximum recovery strain to about 3\% (Ref 9). Nowadays, powder metallurgy (PM) techniques such as mechanical alloying (MA) as well as additive manufacturing (AM) are gaining popularity due to the possibility of fabricating elements with complicated shapes and superior mechanical properties (Ref 10-13).

The powder metallurgy route based on mechanical alloying of pure metal powders followed by consolidation using spark plasma sintering (SPS) is a promising method of preparing a wide range of alloys, in particular when alloying elements have a wide difference in melting points. Moreover, by controlling the processing parameters such as sintering temperature or by introducing space holder materials, porous materials can be obtained, which allow controlling the elastic modulus of the material. Introducing of pore structure to the conventional $\mathrm{NiTi}$ SMAs allows obtaining better biocompatibility as a result of reduction in elastic modulus close to the bone values and the ability to grow cells inside the pores (Ref 14). In the case of powder metallurgy processes, the oxygen and nitrogen contaminations have a significant impact on $M_{\mathrm{s}}$ temperature of Ti- 
$\mathrm{Nb}$-based alloys as well as superelastic properties. It was confirmed that an addition of 1 at. $\%$ of $\mathrm{O}$ to the Ti-Nb alloys leads to a decrease in $M_{\mathrm{s}}$ temperature by about $160{ }^{\circ} \mathrm{C}$ (Ref 15 , 16). Similarly, an addition of 1 at.\% of $\mathrm{N}$ decreases $M_{\mathrm{s}}$ temperature by about $200{ }^{\circ} \mathrm{C}(\operatorname{Ref} 17)$. This is the reason why the martensitic transformation is not observed in sintered materials even if the $\mathrm{Nb}$ content indicates that $M_{\mathrm{s}}$ temperature is close to RT. For example, Lai et al. (Ref 10) show that stable RT superelastic properties can be obtained in binary Ti$\mathrm{Nb}$ alloys prepared by powder metallurgy route by reducing $\mathrm{Nb}$ content to about $13 \%$. Yuan et al. (Ref 18) reported high recovery strain of $5.4 \%$ in $\mathrm{Ti}-11 \mathrm{Nb}$ alloy containing 4 at. $\%$ of oxygen, obtained by mechanical alloying and pressureless sintering. Therefore, in order to obtain superelastic properties in binary $\mathrm{Ti}-\mathrm{Nb}$ alloys obtained by powder metallurgy route, the $\mathrm{Nb}$ concentration has to be reduced to compensate the effect of interstitial atoms on the $M_{\mathrm{s}}$ temperature.

In the presented work, two different compositions of the alloy, containing 14 and 20 at.\% of $\mathrm{Nb}$, were chosen based on the typical oxygen content observed in mechanically alloyed Ti-Nb-based alloys, which is in the range 1.0-2.5 at.\% (Ref 10, $19,20)$. The third alloy containing 26 at. $\%$ of $\mathrm{Nb}$ was chosen as a reference material in which superelastic behavior is observed in the as-cast state. Because of limited information about the evolution of properties of PM-fabricated $\mathrm{Ti}-\mathrm{Nb}$ alloys, the aim of the presented work is to analyze the influence of $\mathrm{Nb}$ content on the microstructure, mechanical properties and superelastic behavior of $\mathrm{Ti}-\mathrm{Nb}$ alloys.

\section{Experimental}

In the presented study, Ti (150 mesh, 99.9\%) and $\mathrm{Nb}(325$ mesh, 99.8\%) elemental powders, supplied by Alfa Aesar, were used as initial materials. Three different compositions of alloys were prepared using mechanical alloying method- $\mathrm{Ti}-x \mathrm{Nb}$ (where $x=14,20$ and 26 at.\%). Mechanical alloying was conducted using Fritsch Pulverisette 7 planetary ball mill with rotation speed $150 \mathrm{rpm}$ and cemented tungsten carbide containers and balls. The ball-to-power weight ratio was 10:1. Time of milling was $30 \mathrm{~h}$. In order to avoid extensive oxidation of powders during synthesis, all the operations with powders were conducted in a glovebox under protective argon atmosphere $\left(\mathrm{O}_{2}\right.$ and $\left.\mathrm{H}_{2} \mathrm{O}<1 \mathrm{ppm}\right)$. In the next step, powders were consolidated using spark plasma sintering (HP D5/2 FCT System) at $1300{ }^{\circ} \mathrm{C}$ for $30 \mathrm{~min}$ under $35 \mathrm{MPa}$ pressure in argon atmosphere. Samples $20 \mathrm{~mm}$ in diameter and $8 \mathrm{~mm}$ high were obtained. Additional annealing at temperature $1250{ }^{\circ} \mathrm{C}$ for $24 \mathrm{~h}$ was applied in order to improve the homogeneity of sintered samples.

Phase composition of powders and sintered materials was examined using a Philips PW1740 x-ray diffractometer (XRD) using Co-K $\alpha$ radiation. The lattice constant of $\beta$-phase is calculated using Eq 1 (Ref 21):

$a_{\beta}=\frac{\lambda \sqrt{h^{2}+k^{2}+l^{2}}}{2 \sin \theta}$

where $\lambda$ is the wavelength of the $\mathrm{x}$-ray radiation, $h, k$, and $l$ are Miller indices of the diffraction planes and $\theta$ is the Bragg angle. The microstructure of the materials was studied using scanning electron microscopes (SEM) Philips XL-30 and FEI Quanta 3D FEG equipped with EDAX Genesis energy-dispersive $\mathrm{X}$-ray spectrometer (EDS). More detailed microstructure observations and phase analysis were conducted using a Tecnai G2 F20 transmission electron microscope (TEM). Thin samples for TEM observations were prepared using jet-polisher Struers Tenupol-5 in an electrolyte containing of $10 \mathrm{vol} . \%$ of $\mathrm{H}_{2} \mathrm{SO}_{4}$ in methanol at $10^{\circ} \mathrm{C}$. Differential scanning calorimetry (DSC, Q1000 TA Instruments) was used to characterize phase transformation temperatures of the materials. The temperature range was from -100 to $100{ }^{\circ} \mathrm{C}$, and the heating/cooling rate was $20^{\circ} \mathrm{C} / \mathrm{min}$. Samples for compression test were prepared in the form of cylinders $4 \mathrm{~mm}$ in diameter and $6 \mathrm{~mm}$ high. Tests were performed using Shimadzu Autograph AG-X plus testing machine at strain rate $10^{-3} 1 / \mathrm{s}$.

\section{Results and Discussion}

\subsection{Powders Characterization After Milling}

The XRD patterns of powders, using the Ti-26Nb alloy as an example, at various stages of mechanical alloying are shown in Fig. 1(a). During the synthesis, the amount of hexagonal $\alpha$ -

(a)
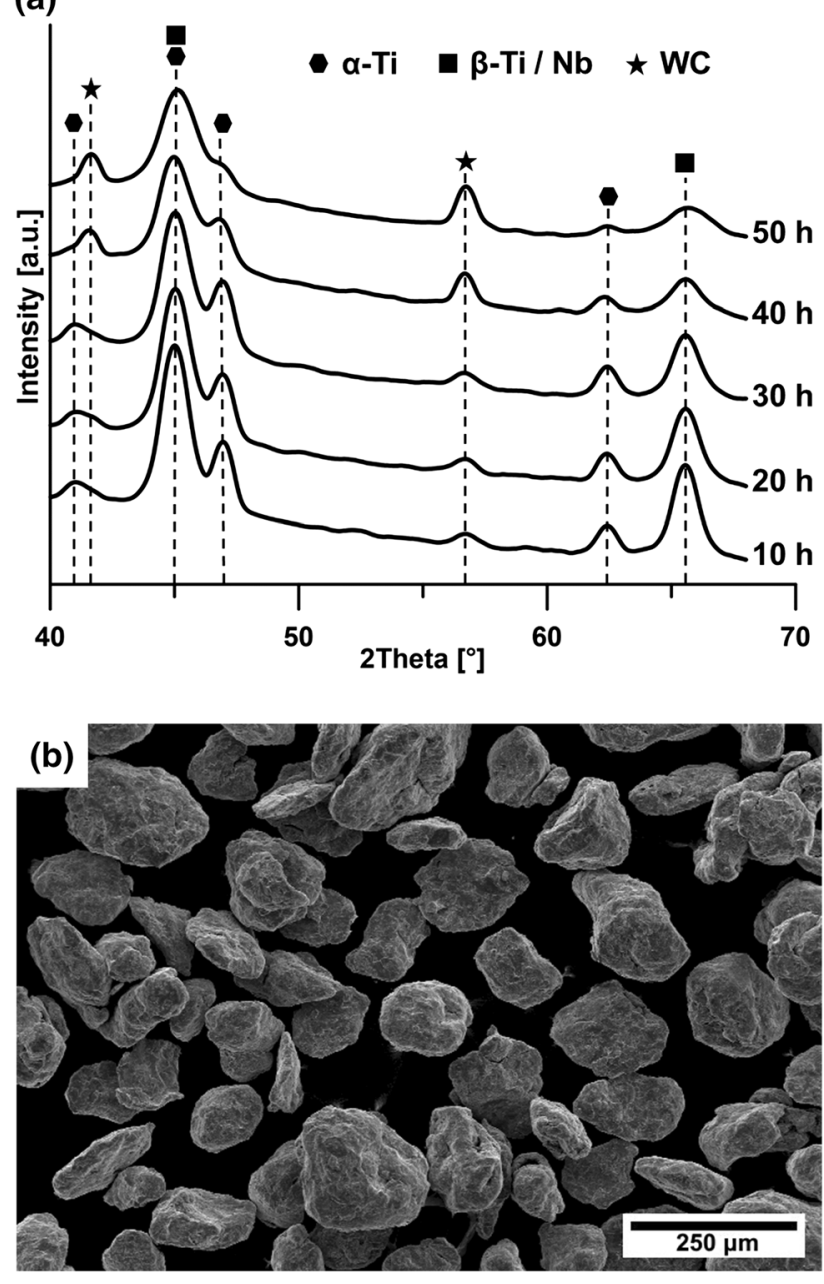

Fig. 1 XRD patterns of powders at various stages of MA (a) and SEM-SE image of the powder after $30 \mathrm{~h}$ of MA (b), on example of $\mathrm{Ti}-26 \mathrm{Nb}$ alloy 
phase decreases with milling time and after $50 \mathrm{~h}$ only trace amount of this phase is observable. $\beta$-Ti as well as $\mathrm{Nb}$ crystalize in the W-type structure in the space group $\mathrm{Im}-3 \mathrm{~m}$, with slight difference in lattice parameters $\left(a_{\beta-\mathrm{Ti}}=3.327 \AA\right.$ and $a_{\mathrm{Nb}}=3.305 \AA$ ); therefore, it is difficult to distinguish them using XRD technique (Ref 22, 23). The observed broadening of peaks during the milling results from the slight deviation of lattice constants connected with severe plastic deformation of powder particles as well as alloying process. It is worth mentioning that, during the synthesis, hexagonal WC phase appears and its amount increases with milling time. The origin of this phase is a result of wear process of cemented tungsten carbide container and milling balls. In order to balance the alloying and wear process, an intermediate time of $30 \mathrm{~h}$ was used for powders prepared for sintering. The selected time allows obtaining sufficient level of mixing of the elemental powder and ensures low level of contaminations from the wear process. As shown in Fig. 1(b), the morphology of the obtained powder is close to spherical with average grain size of about $100 \mu \mathrm{m}$.

\subsection{As-Sintered Alloys}

The XRD patterns of the as-sintered materials are shown in Fig. 2. In all alloys, mainly regular $\beta$-phase is observed after sintering. Only small amount of hexagonal $\alpha$-phase is present in the samples. The trace amount of orthorhombic martensite $\alpha$ " phase is observed in the case of alloys containing 14 and 20 at.\% of $\mathrm{Nb}$. It is worth noticing that the WC phase observed in powders after mechanical alloying is not observed in sintered materials. It is possible that WC particles were dissolved in the matrix during sintering (Ref 24). In the microstructure of the obtained alloys, equiaxed $\beta$-phase grains with size in range of 10-50 $\mu \mathrm{m}$ are observed, as shown in Fig. 3, in the case of Ti$14 \mathrm{Nb}$ alloy. At the grain boundaries, darker areas of $\alpha$-phase, depleted in $\mathrm{Nb}$, are present. Based on metallographic analysis, as described in (Ref 25), it was determined that the amount of $\alpha$-phase decreases with $\mathrm{Nb}$ content from 2.6 vol. $\%$ in the case of Ti-14Nb to 0.9 vol.\% for Ti-26Nb. Moreover, very bright areas, containing mainly $\mathrm{Nb}$, are observed, which are attributed to undissolved particles of $\mathrm{Nb}$ during sintering. The presence of these particles causes a reduction in $\mathrm{Nb}$ content in the matrix. In the case of $\mathrm{Ti}-14 \mathrm{Nb}$ at this stage, the average $\mathrm{Nb}$ content in $\beta$ grains is 13.3 at.\%. Applied sintering conditions allowed to obtain highly dense samples with porosity below 0.5 vol. $\%$.

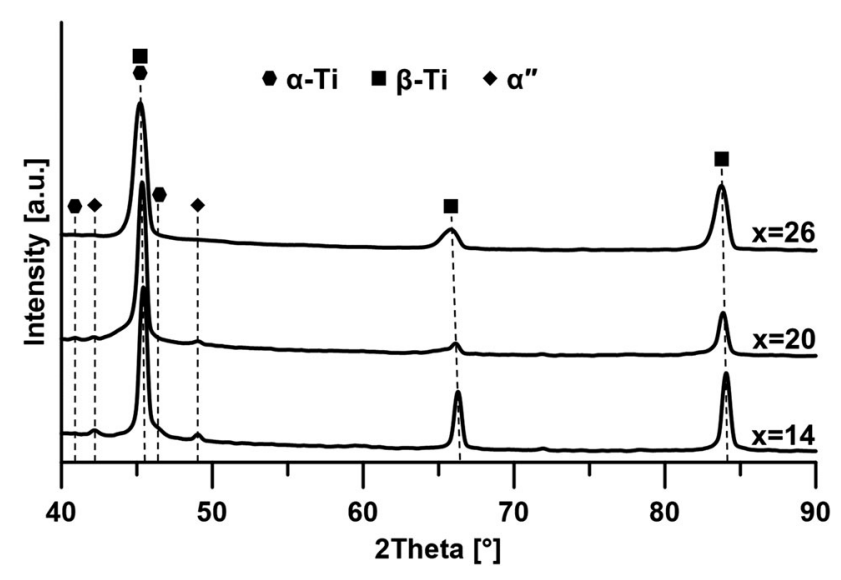

Fig. 2 XRD patterns of the as-sintered $\mathrm{Ti}-x \mathrm{Nb}$ alloys
The existence of $\alpha$-phase at the grain boundaries of $\beta$-grains was confirmed using TEM studies (Fig. 4). Bright-field (BF) image shows a thin layer, about $500 \mathrm{~nm}$, of $\alpha$-phase between two grains of $\beta$-phase. The presence of hexagonal $\alpha$-phase in sintered $\mathrm{Ti}-\mathrm{Nb}$ alloys was also observed by other authors, even if $\mathrm{Nb}$ content in alloys was much higher than the one required to obtain one-phase $\beta$-alloys ( $\operatorname{Ref} 11,26)$. The $\alpha$-phase is harder and more brittle in comparison with regular $\beta$-phase. For that reason, it is used to increase the mechanical properties of near $\beta$-Ti alloys, whereas $\beta$-phase maintains good plastic properties, e.g., Ti-10V-2Fe-3Al or Ti-15V-3Cr-3Sn-3Al (Ref 27, 28). In the case of the investigated alloys, $\alpha$-phase is undesirable, because it can lead to nucleation of cracks at the grain boundaries during deformation, which can reduce the superelastic properties of the alloys. The existence of $\alpha$-Ti phase and $\mathrm{Nb}$ particles is a result of insufficient interdiffusion of $\mathrm{Ti}$ and $\mathrm{Nb}$ during the sintering process. Therefore, in order to improve the homogeneity of the as-sintered alloys additional heat treatment at temperature of $1250{ }^{\circ} \mathrm{C}$ for $24 \mathrm{~h}$ was applied.

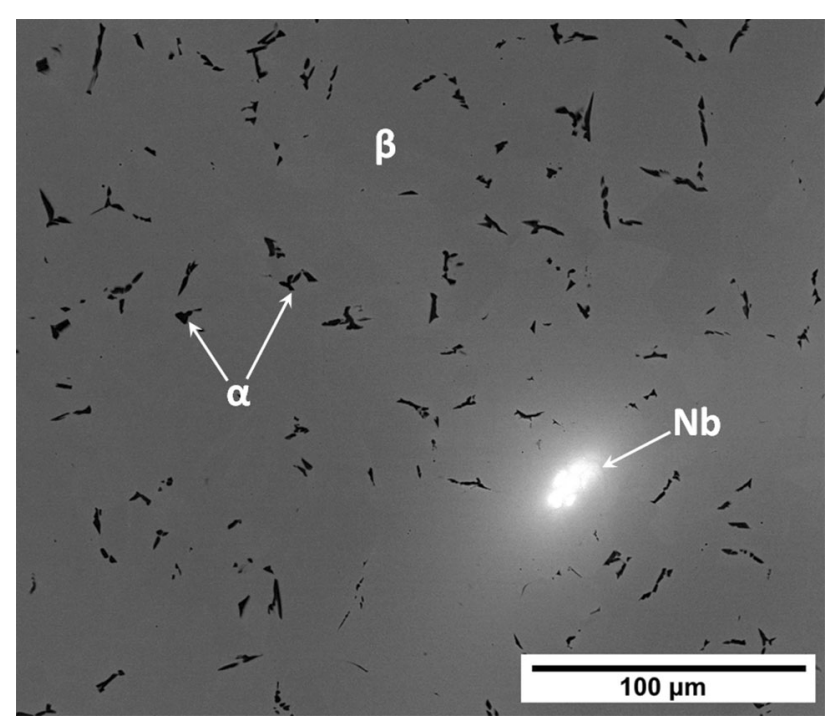

Fig. 3 Typical microstructure of the as-sintered alloys on the example of $\mathrm{Ti}-14 \mathrm{Nb}$ alloy

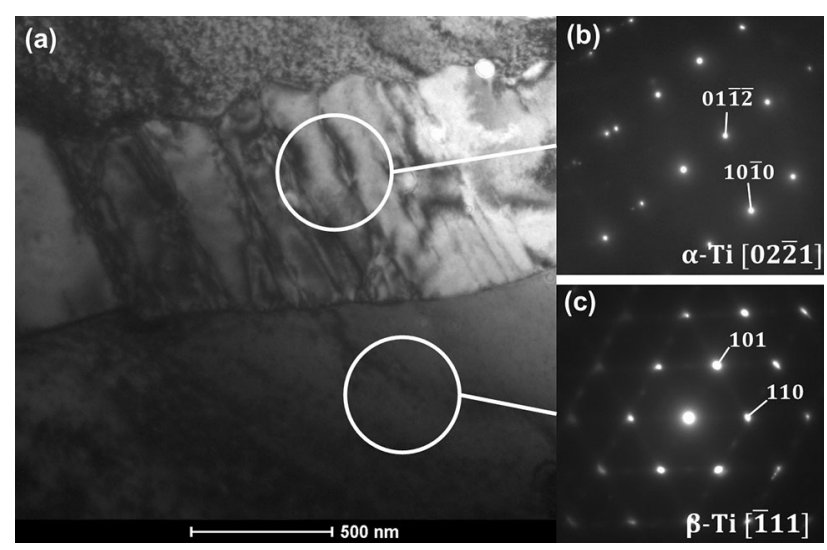

Fig. 4 TEM-BF image of thin layer of $\alpha$-phase between two $\beta$ phase grains (a) and corresponding SAED patterns (b, c) from areas marked with circles 


\subsection{Heat-Treated Alloys}

The typical microstructure of heat-treated sample is presented in Fig. 5. Additional annealing leads to increase in homogeneity of the materials. The $\mathrm{Nb}$-rich areas were dissolved in the matrix during this process. As a result, the concentration of $\mathrm{Nb}$ in $\beta$ matrix was increased and reached the value close to initial composition of powders $-14.8 \pm 0.3$ at. $\%$ in the case of Ti-14Nb alloy, $20.5 \pm 0.6$ at. $\%$ for $\mathrm{Ti}-20 \mathrm{Nb}$ and $26.7 \pm 0.3$ at. $\%$ for Ti-26Nb. In addition, slight grain growth of $\beta$-phase was observed. Annealing leads to the change in morphology of the $\alpha$-phase from precipitations at the grain boundaries (Fig. 3) to colony of isolated $\alpha$-grains-darker grains in Fig. 5. The amount of the $\alpha$-phase was reduced to about $0.5 \mathrm{vol} . \%$ in the case of all materials. Hexagonal $\alpha$-phase could not be completely dissolved in the matrix during the hightemperature annealing due to presence of contaminations. It was confirmed, using EDS technique, that the concentration of carbon in $\alpha$-phase areas is much higher in comparison with $\beta$ phase areas. It is well known that carbon highly stabilizes $\alpha$ phase, therefore the $\alpha$-phase areas can exist even after longterm annealing (Ref 29). Carbon is observed in obtained

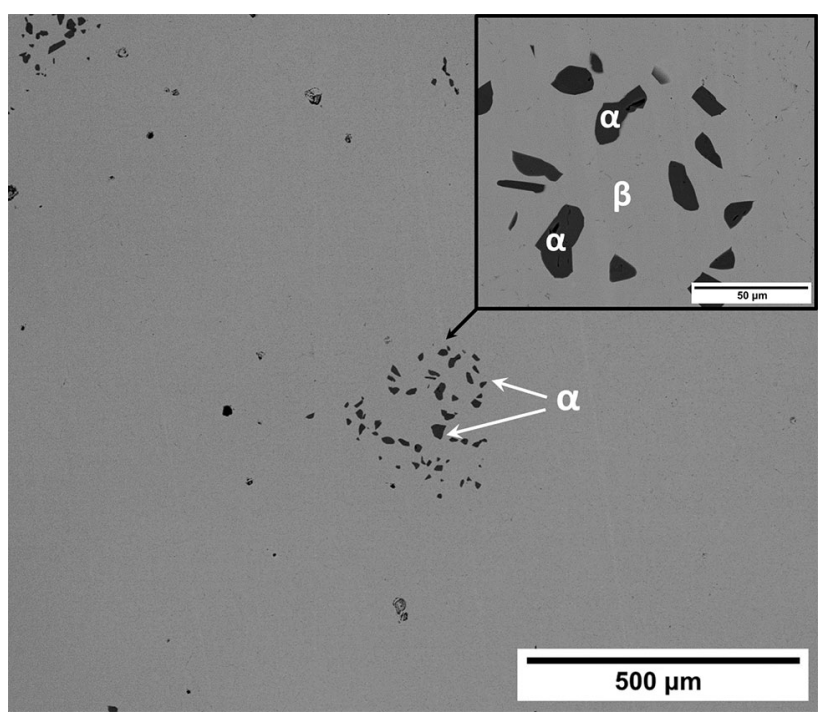

Fig. 5 Typical microstructure of heat-treated alloys on the example of Ti-14Nb alloy

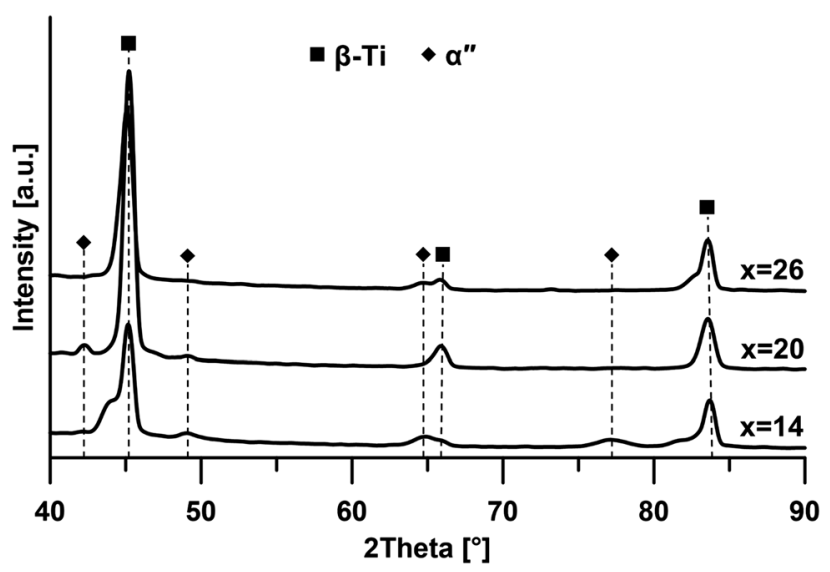

Fig. 6 XRD patterns of heat-treated Ti- $x \mathrm{Nb}$ alloys materials as a result of dissolution of the WC particles, observed in powder before sintering (Fig. 1a), and come from wear process of reactor and milling balls during mechanical alloying. Chemical analysis of the matrix shows that it contains

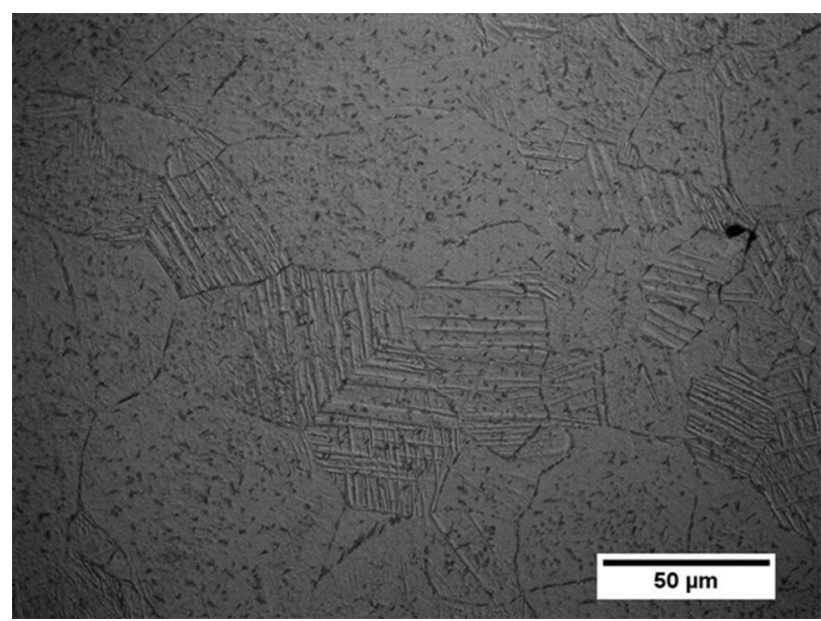

Fig. $7 \mathrm{OM}$ microstructure of Ti-14Nb alloy after heat treatment
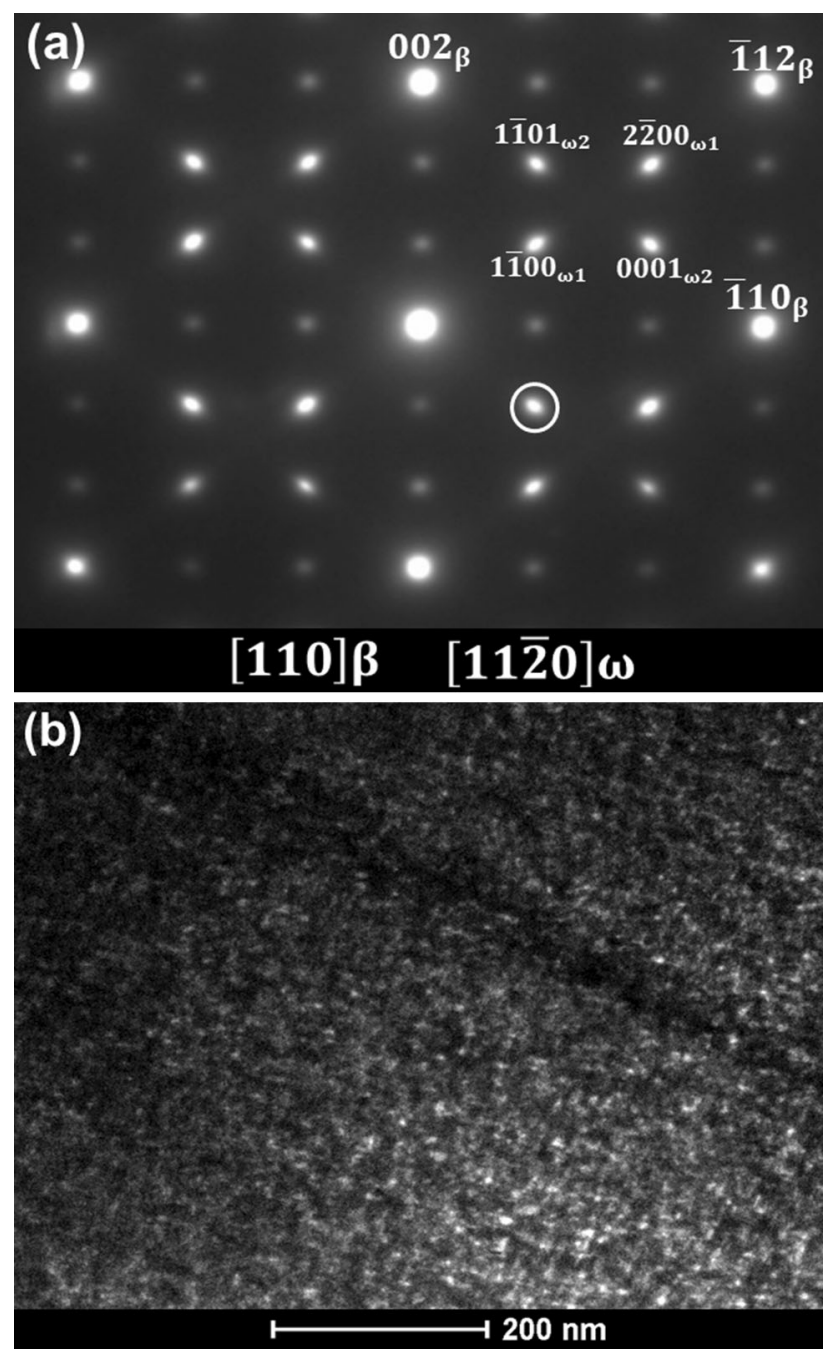

Fig. 8 SAED pattern (a) and corresponding DF TEM image (b) of heat-treated $\mathrm{Ti}-14 \mathrm{Nb}$ alloy 
about 1 at.\% of $\mathrm{W}$ which confirms that the WC particles were dissolved during the sintering. At this stage, the measured porosity was 0.5 vol. $\%$ in the case of all materials, similar to the materials in the as-sintered condition.

The phase analysis, shown in Fig. 6, confirms that the applied heat treatment resulted in a reduced amount of hexagonal $\alpha$-phase-peaks connected with $\alpha$-phase are not observed after heat treatment. In all of the alloys, regular $\beta$ phase is observed. The lattice parameter of $\beta$-phase, calculated based on Eq 1, is $2.325 \AA$ for Ti-14Nb, $2.326 \AA$ for Ti-20Nb and $2.325 \AA$ for $\mathrm{Ti}-26 \mathrm{Nb}$ alloy, which is in good agreement with others research (Ref 3). However, in the case of Ti-20Nb and $\mathrm{Ti}-14 \mathrm{Nb}$ martensitic transformation has taken place during cooling after heat treatment. This observation was also confirmed by microscopic observation. Figure 7 shows an optical microscopy (OM) image of the microstructure of the heat-treated $\mathrm{Ti}-14 \mathrm{Nb}$ alloy etched by Kroll's reagent. In the microstructure of these alloys, a martensitic phase exceptionally can be observed inside grains of $\beta$-phase, which suggest that $M_{\mathrm{s}}$ temperature of this alloy is close to RT.

TEM observations of heat-treated alloys, similar to the assintered materials, reveal the existence of nanoprecipitations of the hexagonal $\omega$-phase. There are two types of $\omega$-phase in titanium alloys-thermal $\omega$-phase which is formed during aging at intermediate temperatures and athermal $\omega$-phase which is observed in solution-treated alloys ( $\operatorname{Ref} 30,31$ ). Both of these phases affect the properties of titanium alloys, e.g., an increase in the hardness from $200 \mathrm{HV}$ to $440 \mathrm{HV}$ during annealing of Ti-30Nb alloy was observed, as a result of thermal $\omega$-phase formation (Ref 2). Because of the formation process of the $\omega$ phase, described in more details in (Ref 32), there are four different variants of $\omega$-phase, which have the orientation relationship with the parent $\beta$-phase as follows: $\{0001\}_{\omega} / /$ $\{111\}_{\beta}(\operatorname{Ref} 11-20){ }_{\omega} / /[110]_{\beta}$ (Ref 3). Figure 8 shows darkfield (DF) TEM image and corresponding SAED pattern of heat-treated $\mathrm{Ti}-14 \mathrm{Nb}$ alloy. The SAED pattern was obtained from the $[110]_{\beta}$ zone axis. In addition to the primary reflections from the $\beta$ matrix, diffused scattering corresponding with the athermal $\omega$-phase at $1 / 3\{112\}_{\beta}$ positions was observed. DF image obtained using $\omega$-phase reflection, marked by circle in Fig. 8(a), indicates that $\omega$-phase in the investigated alloys appears in the form of nanometric precipitations, uniformly distributed in the $\beta$-phase matrix. The presence of $\omega$-phase in Ti-Nb alloys was also described by other authors (Ref 33, 34). The dispersed $\omega$-particles increase the strength of the alloys, but on the other hand mechanically suppress the martensitic

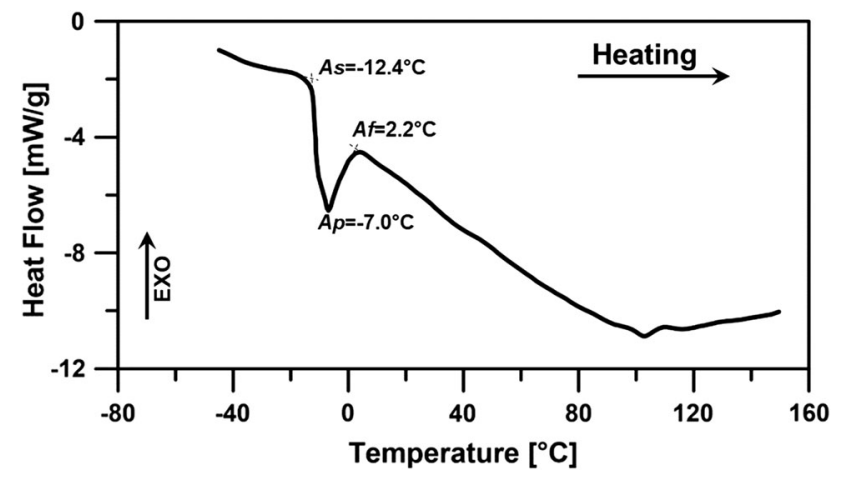

Fig. 9 DSC heating curve of heat-treated Ti-14Nb alloy transformation, resulting in a decrease in the martensitic transformation temperature (Ref 3 ).

Thermal analysis was carried out in order to determine the temperature range of reversible $\beta \leftrightarrow \alpha^{\prime \prime}$ martensitic transformation in investigated alloys. Figure 9 show the DSC heating curve of the Ti-14Nb alloy after heat treatment. Determined for this alloy $A_{\mathrm{s}}$ and $A_{\mathrm{f}}$ temperatures are -12.4 and $2.2{ }^{\circ} \mathrm{C}$, respectively. These values are in agreement with other works, e.g., Lai et al. (Ref 10) showed martensitic transformation in the temperature about $0{ }^{\circ} \mathrm{C}$ in sintered Ti-14Nb alloy. Although the $A_{\mathrm{s}}$ temperature for this composition lies below RT, $\alpha^{\prime \prime}$ martensite can be observed in the microstructure of the alloy (Fig. 6 and 7) as a result of possible residual stresses after heat treatment. There were no observable effects connected with martensitic transformation in the case of alloys containing 20 and 26 at. $\%$ of $\mathrm{Nb}$ in the temperature range from -100 to $100{ }^{\circ} \mathrm{C}$. It is probable that for these alloys, temperature range of
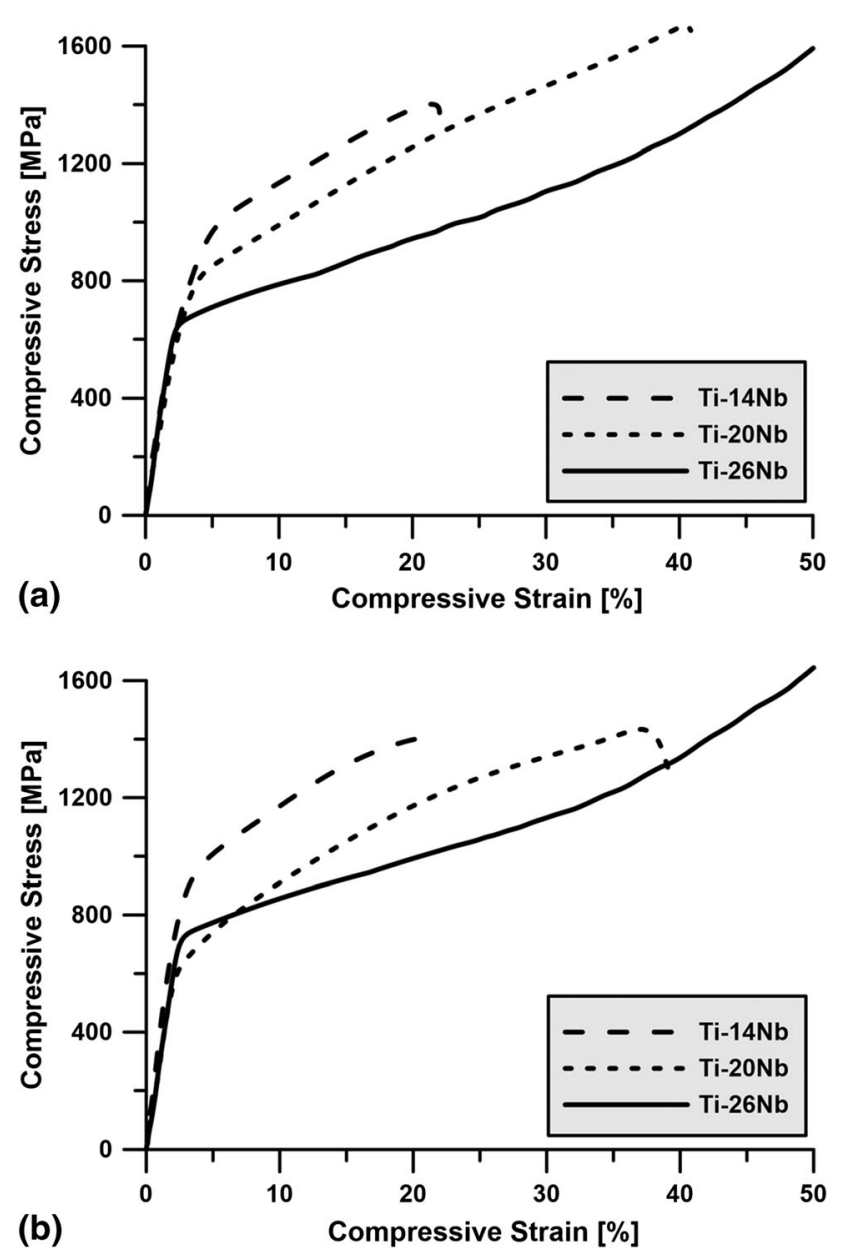

Fig. 10 Compressive stress-strain curves of Ti- $x \mathrm{Nb}$ alloys in the as-sintered (a) and heat-treated (b) states

Table 1 Mechanical properties of investigated alloys

\begin{tabular}{lccc}
\hline & \multicolumn{3}{c}{ Yield strength, MPa } \\
\cline { 2 - 4 } & Ti-14Nb & Ti-20Nb & Ti-26Nb \\
\hline As-sintered & $949 \pm 36$ & $746 \pm 19$ & $656 \pm 10$ \\
Heat-treated & $921 \pm 30$ & $624 \pm 26$ & $710 \pm 14$ \\
\hline
\end{tabular}


martensitic transformation lies much below RT. For example, $M_{\mathrm{S}}$ temperature for sintered $\mathrm{Ti}-18 \mathrm{Nb}$ was extrapolated to about $-160{ }^{\circ} \mathrm{C}(\operatorname{Ref} 10)$.

\subsection{Mechanical Properties}

The compression tests were carried out in order to determine the mechanical properties of obtained alloys. Compression curves of the as-sintered alloys, presented in Fig. 10(a), show that yield strength (YS) of the investigated alloys, listed in Table 1, decreases with $\mathrm{Nb}$ content. On the other hand, compressive strain increases with $\mathrm{Nb}$ content and in the case of alloy containing 26 at.\% of $\mathrm{Nb}$ exceeds 50\%. This dependence is connected with the presence of hexagonal $\alpha$ phase in the microstructure of the as-sintered materials, as described in paragraph 3.2. With increasing $\mathrm{Nb}$ concentration, the amount of the $\alpha$-phase decreases and as a result the YS decreases and the plasticity increases.

Figure 10(b) shows compressive curves of heat-treated materials. Although the applied heat treatment leads to an increase in the homogeneity of the materials, only small changes in mechanical properties were observed. In the case of alloys containing 14 and 20 at.\% of $\mathrm{Nb}$, a slight decrease in YS was noted. On the other hand, for Ti-26Nb alloy, the YS increased by about $50 \mathrm{MPa}$. No changes were observed in compression strain. Slight difference in the mechanical properties between the as-sintered and heat-treated materials can be attributed to a few processes taking place during the annealing. First of all, annealing leads to grain growth, which can reduce the properties of the alloys, as described by the Hall-Petch relationship. Simultaneously, the reduction in amount of hexagonal $\alpha$-phase precipitations, as well as, undissolved $\mathrm{Nb}$ particles, which also had influence on mechanical properties, was observed. On the other hand, the formation of nanometric precipitations of $\omega$-phase during high-temperature annealing leads to an increase in mechanical properties (Ref 8). It is important to note that $\mathrm{Ti}-\mathrm{Nb}$ alloys obtained by casting techniques exhibit much lower mechanical properties in comparison with obtained alloys. YS of casted and solutiontreated alloys typically did not excess $400 \mathrm{MPa}(\operatorname{Ref} 8,35)$, whereas this value for alloys obtained by powder metallurgy route typically exceeded $1000 \mathrm{MPa}$ (Ref 19, 36). There are several possible reasons describing the increased mechanical properties of alloy obtained by powder metallurgy route in comparison with cast alloys. First of all, the oxygen and nitrogen contaminations caused the solution-hardening effect, which increases mechanical properties of the alloy, e.g., addition of 2 at.\% of oxygen to Ti- $22 \mathrm{Nb}$ alloy increases the fracture stress of the alloy to $1.37 \mathrm{GPa}$ (Ref 9). Secondly, the observed $\alpha$-phase precipitations in fabricated alloys also lead to an increase in the mechanical properties, as in the case of near$\beta$ Ti alloys (Ref 27). The frequently observed, in the case of mechanically alloyed materials, nanoparticles of oxides also can increase the properties of the materials (Ref 37).

In order to determine the superelastic properties of the investigated alloys, cyclic compression tests were carried out. At the first cycle, compressive strain reached $1 \%$ and then the stress was removed. The tests were repeated, for the same sample, by increasing strain by $0.5 \%$, for every cycle, up to $5 \%$. Test was carried out at room temperature. The maximum recoverable strain as high as $3 \%$ was obtained in the case of Ti$14 \mathrm{Nb}$ alloy, as shown in Fig. 11. Recoverable strain for alloys with 20 and 26 at.\% of $\mathrm{Nb}$ was 2.2 and $1.9 \%$, respectively.

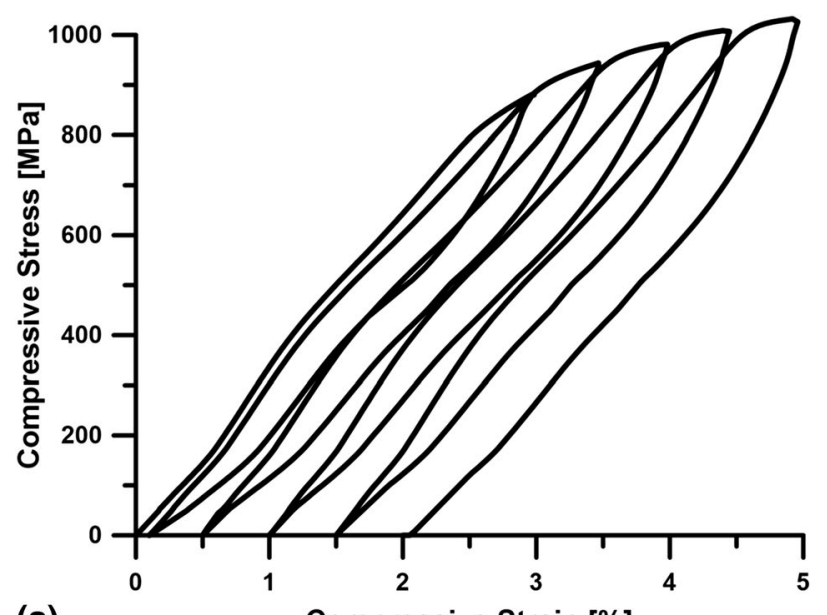

(a)

Compressive Strain [\%]
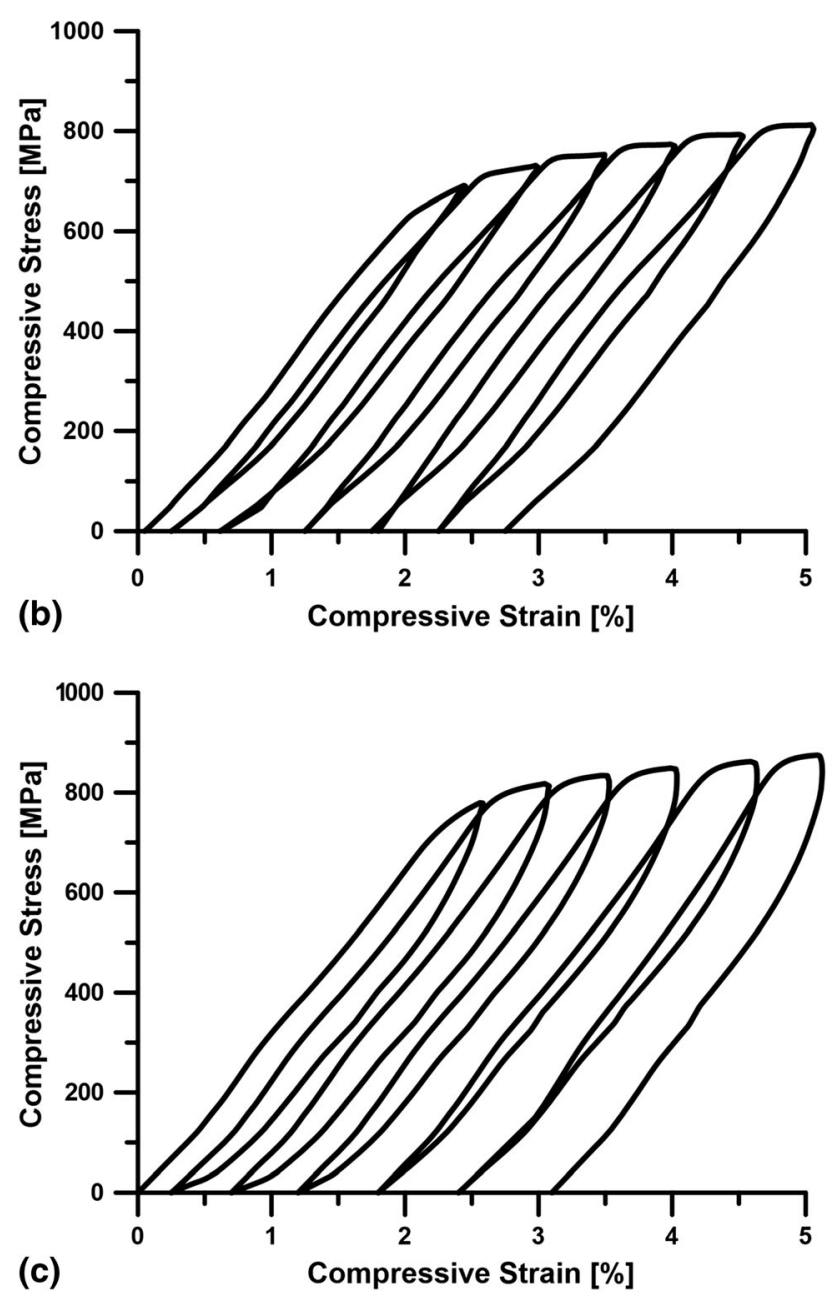

Fig. 11 Compressive stress-strain curves obtained by cyclic loading-unloading test of the heat-treated Ti-14Nb (a), Ti-20Nb (b) and $\mathrm{Ti}-26 \mathrm{Nb}(\mathrm{c})$

Total recoverable strain is composed of three parts: the recovery of its own elasticity $\left(R_{\mathrm{E}}\right)$, the elastic recovery of pore structure $\left(\mathrm{R}_{\mathrm{P}}\right)$ and recovery connected with reversible martensitic transformation $\left(R_{\mathrm{MT}}\right)$ (Ref 10$)$. The porosity of fabricated materials is low (does not exceed $0.2 \%$ ), therefore $R_{\mathrm{P}}$ part can be neglected. In the case of Ti-20Nb and Ti-26Nb alloys, $A_{\mathrm{s}}$ 
and $A_{\mathrm{f}}$ are far away from the room temperature, and hence the determined recovery strain is connected mainly with the $R_{\mathrm{E}}$ part. It is well known that the elasticity of the $\beta$-phase Ti alloys is generally high when it contains an elevated amount of oxygen (Ref 38, 39). The superelastic behavior was observed only for alloy containing 14 at.\% of $\mathrm{Nb}$. DSC measurements show that $A_{\mathrm{s}}$ and $A_{\mathrm{f}}$ temperatures, of this alloy, are slightly below room temperature, which should provide the optimal superelastic properties. The obtained value is close to the superelasticity of solution-treated alloys fabricated by casting methods, e.g., Kim et al. (Ref 3 ) reported a maximum recovery strain of $2.5 \%$ in cold-rolled and solution-treated $\mathrm{Ti}-26 \mathrm{Nb}$ alloy; however, the $R_{\mathrm{E}}$ in the case of alloys obtained by powder metallurgy techniques is much higher in comparison with cast alloys, because of low critical stress for slip deformation in the case of cast alloys.

\section{Conclusions}

In order to determine the influence of $\mathrm{Nb}$ content on the microstructure, mechanical properties and superelastic behavior of $\beta$-type Ti-Nb alloys, mechanical alloying followed by spark plasma sintering techniques were used to prepare $\mathrm{Ti}-x \mathrm{Nb}$ (where $x=26,20,14$ ) alloys. The obtained results are as follows:

(1) The applied sintering conditions (temperature $1300{ }^{\circ} \mathrm{C}$, pressure $35 \mathrm{MPa}$, time $30 \mathrm{~min}$ ) allow to obtain dense samples, with porosity below 0.5 vol. $\%$; however, additional annealing at $1250{ }^{\circ} \mathrm{C}$ for $24 \mathrm{~h}$ had to be applied in order to increase the homogeneity of the as-sintered materials. As a result, the concentration of $\mathrm{Nb}$ in the matrix reached the value close to the intended, and amount of hexagonal $\alpha$-phase was reduced to about 0.5 vol. $\%$.

(2) Mechanical properties of fabricated alloys are higher in comparison with cast Ti-Nb alloys. YS of the as-sintered alloys decreases with $\mathrm{Nb}$ content from $950 \mathrm{MPa}$ for $\mathrm{Ti}^{-}$ $14 \mathrm{Nb}$ to $650 \mathrm{MPa}$ for Ti-26Nb, as a result of decrease in the volume fraction of $\alpha$-phase with $\mathrm{Nb}$ content. Heat treatment has no significant effect on mechanical properties of the alloys.

(3) Superelastic behavior at RT was observed for heat-treated Ti-14 alloy. This alloy exhibited maximum recoverable strain up to $3 \%$. Determined for this alloy, by DSC technique, $A_{\mathrm{s}}$ and $A_{\mathrm{f}}$ temperatures were -12.4 and $2.2{ }^{\circ} \mathrm{C}$, respectively.

\section{Acknowledgments}

The research was co-financed by the European Union from resources of the European Social Fund (Project No.WNDPOWR.03.02.00-00-I043/16).

\section{Open Access}

This article is distributed under the terms of the Creative Commons Attribution 4.0 International License (http://creativeco mmons.org/licenses/by/4.0/), which permits unrestricted use, distribution, and reproduction in any medium, provided you give appropriate credit to the original author(s) and the source, provide a link to the Creative Commons license, and indicate if changes were made.

\section{References}

1. B.L. Wang, L. Li, and Y.F. Zheng, In Vitro Cytotoxicity and Hemocompatibility Studies of Ti-Nb, Ti-Nb-Zr and Ti-Nb-Hf Biomedical Shape Memory Alloys, Biomed. Mater., 2010, 5(4), p 04410

2. E.S.N. Lopes, A. Cremasco, C.R.M. Afonso, and R. Caram Lopes, Effects of Double Aging Heat Treatment on the Microstructure, Vickers Hardness and Elastic Modulus of Ti-Nb Alloys, Mater. Charact., 2011, 62(7), p 673-680

3. H.Y. Kim, Y. Ikehara, J.I. Kim, H. Hosoda, and S. Miyazaki, Martensitic Transformation, Shape Memory Effect and Superelasticity of Ti-Nb Binary Alloys, Acta Mater., 2006, 54(9), p 24192429

4. D. Kuroda, M. Niinomi, M. Morinaga, Y. Kato, and T. Yashiro, Design and Mechanical Properties of New $\beta$ Type Titanium Alloys for Implant Materials, Mater. Sci. Eng. A, 1998, 243(1-2), p 244-249

5. H.Y. Kim, S. Hashimoto, J.I. Kim, H. Hosoda, and S. Miyazaki, Mechanical Properties and Shape Memory Behavior of Ti-Nb Alloys, Mater. Trans., 2004, 45(7), p 2443-2448

6. H.Y. Kim and S. Miyazaki, Several Issues in the Development of TiNb-Based Shape Memory Alloys, Shape Mem. Superelast., 2016, 2(4), p 380-390

7. A. Cremasco, P.N. Andrade, R.J. Contieri, E.S.N. Lopes, C.R.M. Afonso, and R. Caram, Correlations Between Aging Heat Treatment, $\omega$ Phase Precipitation and Mechanical Properties of a Cast Ti-Nb Alloy, Mater. Des., 2011, 32(4), p 2387-2390

8. H.Y. Kim, J.I. Kim, T. Inamura, H. Hosoda, and S. Miyazaki, Effect of Thermo-mechanical Treatment on Mechanical Properties and Shape Memory Behavior of Ti-(26-28) at.\% Nb Alloys, Mater. Sci. Eng. A, 2006, 438, p 839-843

9. J.I. Kim, H.Y. Kim, H. Hosoda, and S. Miyazaki, Shape Memory Behavior of Ti-22Nb-(0.5-2.0) O (at\%) Biomedical Alloys, Mater. Trans., 2005, 46(4), p 852-857

10. M. Lai, Y. Gao, B. Yuan, and M. Zhu, Remarkable Superelasticity of Sintered Ti-Nb Alloys by $M_{\mathrm{S}}$ Adjustment Via Oxygen Regulation, Mater. Des., 2015, 87, p 466-472

11. B. Sharma, S.K. Vajpai, and K. Ameyama, Microstructure and Properties of Beta Ti-Nb Alloy Prepared by Powder Metallurgy Route Using Titanium Hydride Powder, J. Alloys Compd., 2016, 656, p 978986

12. Y.J. Liu, Y.S. Zhang, and L.C. Zhang, Transformation-Induced Plasticity and High Strength in Beta Titanium Alloy Manufactured by Selective Laser Melting, Materialia, 2019, 6, p 100299

13. J.C. Wang, Y.J. Liu, P. Qin, S.X. Liang, T.B. Sercombe, and L.C. Zhang, Selective Laser Melting of Ti-35Nb Composite from Elemental Powder Mixture: Microstructure, Mechanical Behavior and Corrosion Behavior, Mater. Sci. Eng., A, 2019, 760, p 214-224

14. S. Kujala, J. Ryhänen, A. Danilov, and J. Tuukkanen, Effect of Porosity on the Osteointegration and Bone Ingrowth of a WeightBearing Nickel-Titanium Bone Graft Substitute, Biomaterials, 2003, 24(25), p 4691-4697

15. M. Tahara, H.Y. Kim, T. Inamura, H. Hosoda, and S. Miyazaki, Lattice Modulation and Superelasticity in Oxygen-Added $\beta$-Ti Alloys, Acta Mater., 2011, 59(16), p 6208-6218

16. S. Miyazaki, H.Y. Kim, and H. Hosoda, Development and Characterization of Ni-Free Ti-Base Shape Memory and Superelastic Alloys, Mater. Sci. Eng. A, 2006, 438, p 18-24

17. M. Tahara, H.Y. Kim, H. Hosoda, and S. Miyazaki, Shape Memory Effect and Cyclic Deformation Behavior of Ti-Nb-N Alloys, Funct. Mater. Lett., 2009, 2(02), p 79-82

18. B. Yuan, B. Yang, Y. Gao, M. Lai, X.H. Chen, and M. Zhu, Achieving Ultra-High Superelasticity and Cyclic Stability of Biomedical Ti-11Nb$4 \mathrm{O}$ (at.\%) Alloys by Controlling Nb and Oxygen Content, Mater. Des., 2016, 92, p 978-982 
19. L.M. Zou, C. Yang, Y. Long, Z.Y. Xiao, and Y.Y. Li, Fabrication of Biomedical Ti-35Nb-7Zr-5Ta Alloys by Mechanical Alloying and Spark Plasma Sintering, Powder Metall., 2012, 55(1), p 65-70

20. J. Málek, F. Hnilica, J. Veselý, and B. Smola, Heat Treatment and Mechanical Properties of Powder Metallurgy Processed Ti-35.5 Nb57Ta Beta-Titanium Alloy, Mater. Charact., 2013, 84, p 225-231

21. B.D. Cullity, S.R. Stock, Elements of X-Ray Diffraction, Vol 3, Prentice Hall, New Jersey, 2001

22. T.B. Massalski, Binary Alloy Phase Diagrams, Vol 2, American Society for Metals, Cleveland, 1986

23. C. Salvo, C. Aguilar, R. Cardoso-Gil, A. Medina, L. Bejar, and R.V. Mangalaraja, Study on the Microstructural Evolution of Ti-Nb Based Alloy Obtained by High-Energy Ball Milling, J. Alloys Compd., 2017, 720, p 254-263

24. D. Liu, P. Hu, and G. Min, Interfacial Reaction in Cast WC Particulate Reinforced Titanium Metal Matrix Composites Coating Produced by Laser Processing, Opt. Laser Technol., 2015, 69, p 180-186

25. C.D. Rabadia, Y.J. Liu, S.F. Jawed, L. Wang, Y.H. Li, X.H. Zhang, T.B. Sercombe, H. Sun, and L.C. Zhang, Improved Deformation Behavior in Ti-Zr-Fe-Mn Alloys Comprising the C14 Type Laves and $\beta$ Phases, Mater. Des., 2018, 160, p 1059-1070

26. R. Karre, B.K. Kodli, A. Rajendran, J. Nivedhitha, D.K. Pattanayak, K. Ameyama, and S.R. Dey, Comparative Study on Ti-Nb Binary Alloys Fabricated Through Spark Plasma Sintering and Conventional P/M Routes for Biomedical Application, Mater. Sci. Eng. C, 2019, 94, p 619-627

27. I. Weiss and S.L. Semiatin, Thermomechanical Processing of Beta Titanium Alloys-An Overview, Mater. Sci. Eng. A, 1998, 243(1-2), p 46-65

28. S. Shekhar, R. Sarkar, S.K. Kar, and A. Bhattacharjee, Effect of Solution Treatment and Aging on Microstructure and Tensile Properties of High Strength $\beta$ Titanium Alloy, Ti-5Al-5V-5Mo-3Cr, Mater. Des., 2015, 66, p 596-610

29. M.J. Donachie, Titanium: A Technical Guide, Cleveland, ASM International, 2000, p 13-21

30. J.J.G. Moreno, M. Bönisch, N.T. Panagiotopoulos, M. Calin, D.G. Papageorgiou, A. Gebert, J. Eckert, G.A. Evangelakis, and C.E. Lekka,
Ab-Initio and Experimental Study of Phase Stability of Ti-Nb Alloys, J. Alloys Compd., 2017, 696, p 481-489

31. Y.F. Xu, D.Q. Yi, H.Q. Liu, B. Wang, and F.L. Yang, Age-Hardening Behavior, Microstructural Evolution and Grain Growth Kinetics of Isothermal $\omega$ Phase of Ti-Nb-Ta-Zr-Fe Alloy for Biomedical Applications, Mater. Sci. Eng. A, 2011, 529, p 326-334

32. S. Miyazaki, My Experience with Ti-Ni-Based and Ti-Based Shape Memory Alloys, Shape Mem. Superelast., 2017, 3(4), p 279-314

33. M.J. Lai, C.C. Tasan, J. Zhang, B. Grabowski, L.F. Huang, and D. Raabe, Origin of Shear Induced $\beta$ to $\omega$ Transition in Ti-Nb-Based Alloys, Acta Mater., 2015, 92, p 55-63

34. D.L. Moffat and D.C. Larbalestier, The Competition Between Martensite and Omega in Quenched Ti-Nb Alloys, Metall. Trans. A, 1988, 19(7), p 1677-1686

35. H.Y. Kim, J. Fu, H. Tobe, J.I. Kim, and S. Miyazaki, Crystal Structure, Transformation Strain, and Superelastic Property of Ti-Nb-Zr and TiNb-Ta Alloys, Shape Mem. Superelast., 2015, 1(2), p 107-116

36. M. Lai, Y. Gao, B. Yuan, and M. Zhu, Indirect Determination of Martensitic Transformation Temperature of Sintered Nickel-Free Ti22Nb-6Zr Alloy by Low Temperature Compression Test, Mater. Des., 2014, 60, p 193-197

37. Y. Long, H. Zhang, T. Wang, X. Huang, Y. Li, J. Wu, H. Chen, and L. Yan, High-Strength Ti-6Al-4V with Ultrafine-Grained Structure Fabricated by High Energy Ball Milling and Spark Plasma Sintering, Mater. Sci. Eng. A, 2013, 585, p 408-414

38. P. Castany, A. Ramarolahy, F. Prima, P. Laheurte, C. Curfs, and T. Gloriant, In Situ Synchrotron X-Ray Diffraction Study of the Martensitic Transformation in Superelastic Ti-24Nb-0.5N and Ti24Nb-0.5 O Alloys, Acta Mater., 2015, 88, p 102-111

39. Q. Wei, L. Wang, Y. Fu, J. Qin, W. Lu, and D. Zhang, Influence of Oxygen Content on Microstructure and Mechanical Properties of TiNb-Ta-Zr Alloy, Mater. Des., 2011, 32(5), p 2934-2939

Publisher's Note Springer Nature remains neutral with regard to jurisdictional claims in published maps and institutional affiliations. 